\title{
Predictors of PTSD symptoms in Brazilian police officers: the synergy of negative affect and peritraumatic dissociation
}

\author{
Deborah B. Maia, ${ }^{1}$ Charles R. Marmar, ${ }^{2}$ Clare Henn-Haase, ${ }^{2}$ Augusta Nóbrega, ${ }^{3}$ \\ Adriana Fiszman, ${ }^{1}$ Carla Marques-Portella, ${ }^{1}$ Mauro V. Mendlowicz, ${ }^{4}$ \\ Evandro S.F. Coutinho, ${ }^{5}$ Ivan Figueira ${ }^{1}$
}

\footnotetext{
1 Instituto de Psiquiatria (IPUB), Universidade Federal do Rio de Janeiro (UFRJ), Brazil.

2 Department of Psychiatry, University of California at San Francisco, San Francisco, USA.

${ }^{3}$ Military Police of the State of Goiás, Brazil.

${ }^{4}$ Department of Psychiatry and Mental Health (MSM), Universidade Federal Fluminense (UFF), Brazil.

${ }^{5}$ Escola Nacional de Saúde Pública (ENSP), Fundação Oswaldo Cruz (FIOCRUZ), Brazil.
}

Received on December 30, 2010; accepted on February 23, 2011

\section{DESCRIPTORS \\ PTSD; \\ Police; \\ Predictors; \\ Negative affect; \\ Peritraumatic; \\ Dissociation.}

\begin{abstract}
Background: Exposure to traumatic events is a necessary but not a sufficient condition for the development of posttraumatic stress disorder (PTSD). Pretrauma, peritrauma and posttrauma factors interact to impact on symptom severity. The aim of the present study is to determine risk factors for PTSD symptoms in Brazilian police officers. Method: In a cross-sectional sample of active duty officers $(n=212)$, participants were asked to complete a socio-demographic questionnaire and self-report scales on affective traits, cumulative critical incident exposure, peritraumatic distress and dissociation, PTSD symptoms, and social support. Hierarchical linear regression analysis was conducted to examine predictors of PTSD symptoms. Results: Variables related to negative affect, job duration, frequency of critical incident exposure, peritraumatic dissociation, and lack of social support remained significant in the final model and explained 55\% of the variance in PTSD symptoms. When interaction terms were evaluated, a synergistic effect between negative affect and peritraumatic dissociation was found. Conclusions: The risk factors found in this study provide clues on how to elaborate primary prevention strategies regarding PTSD symptoms in police officers. Such initiatives may lessen the impact of repeated exposure to traumatic events on police officers over the course of their careers.

(C2011 Elsevier Editora Ltda. All rights reserved.
\end{abstract}


DESCRITORES

TEPT;

Polícia;

Sinais e sintomas;

Afeto;

Transtornos

dissociativos.

\section{Preditores de sintomas de transtorno de estresse pós-traumático em policiais brasileiros: a interação entre afeto negativo e dissociação peritraumática}

\section{Resumo}

Introdução: A exposição a eventos traumáticos é uma condição necessária, porém não única, para o desenvolvimento de transtorno de estresse pós-traumático (TEPT). Fatores individuais pré, peri e pós-trauma exercem impacto sobre a gravidade dos sintomas. O objetivo do presente estudo é determinar os fatores de risco para o desenvolvimento de sintomas de TEPT em policiais brasileiros. Método: Uma amostra transversal de policiais em atividade $(n=212)$ foi convidada a responder um questionário sóciodemográfico e escalas autoaplicáveis sobre afeto positivo e negativo, frequência de incidentes críticos, sofrimento e dissociação peritraumáticos, sintomas de TEPT e apoio social. Regressão linear hierárquica foi utilizada para avaliar fatores de risco. Resultados: Afeto negativo, tempo de trabalho, frequência de exposição a eventos traumáticos, dissociação peritraumática e apoio social diminuído permaneceram no modelo final e explicaram 55\% das variações dos sintomas de TEPT. Foi observado efeito sinérgico entre dissociação peritraumática e afeto negativo. Conclusão: Baseados nos achados os autores discutem estratégias de prevenção que visam diminuir o impacto da exposição a eventos traumáticos em policiais ao longo de suas carreiras.

(c)2011 Elsevier Editora Ltda. Todos os direitos reservados.

\section{Introduction}

Police officers are repeatedly exposed to critical incidents (i.e. duty-related traumatic events), which put them at increased risk for developing posttraumatic stress disorder (PTSD). The prevalence of PTSD in this population varies between $7 \%$ and $19 \%$, and posttraumatic stress symptoms exert a negative impact on physical and mental health, leading to a poorer psychosocial and professional functioning. ${ }^{1-4}$

Several studies have used regression modeling to identify socio-demographic, psychological, work- and trauma-related risk factors for the development of PTSD in police officers. Carlier et al. ${ }^{2}$ investigated risk factors for PTSD in a sample of 262 Dutch officers assessed 3 and 12 months after a critical incident exposure. At 3 months, PTSD was best predicted by introversion, difficulty in expressing feelings, emotional exhaustion at the time of trauma, insufficient time allowed by employer for coming to terms with the trauma, dissatisfaction with organizational support, and insecure job future. On the other hand, lack of hobbies, acute hyperarousal, subsequent traumatic events, job dissatisfaction, and lack of social support were the strongest risk factors at 12 months. In a longitudinal Australian study, the greater severity of critical incident and higher levels of peritraumatic dissociation were found to be associated with specific stress symptoms in 367 policemen. ${ }^{5}$ In a cross-sectional assessment $(n=97)$ of South African officers, ${ }^{6}$ a linear combination of problem-focused coping, emotion-focused coping, and perceived social support best predicted PTSD symptom severity in a model that explained $44.4 \%$ of the variance.

More recently, Marmar et al. ${ }^{7}$ tested a conceptual model for the development of PTSD symptoms emphasizing the role of vulnerability and resilience to peritraumatic panic reactions. Utilizing a hierarchical linear regression model, they were able to explain $39.7 \%$ of the variance in PTSD symptoms in a cross-sectional sample of 715 police officers. Five variables remained significant in the final model: greater peritraumatic distress, greater peritraumatic dissociation, greater problem-solving coping, greater routine work environment stress, and lower levels of social support. They have also tested models of risk in a prospective sample and found that greater routine work environment stress, a positive family psychiatric history, gender, greater trait dissociation, and anger were associated with PTSD symptoms. ${ }^{8-12}$

Although Brazilian police officers are frequently exposed to a wide range of critical incidents, predictors of PTSD still remain unknown in this population. Our aim in the present study is to determine predictive factors of PTSD symptom severity in a sample of active duty Brazilian officers.

\section{Method}

\section{Subjects}

The participants comprise a convenience sample of 300 active duty police officers participating in a specialization course (December-2005) in the city of Goiânia, Brazil. Participants were invited to respond to a self-report questionnaire booklet after signing an informed consent, which insured confidentiality and anonymity. The study was approved by the Internal Review Board of the Instituto de Psiquiatria (IPUB) of the Universidade Federal do Rio de Janeiro (UFRJ). Seventy-nine officers $(26 \%)$ declined to participate in the study. Also, we have excluded all the female police officers $(n=9)$ from the final sample.

\section{Measures}

Self-reports of socio-demographic variables were assessed by a questionnaire designed by the authors. 
The Critical Incident History Questionnaire $(\mathrm{CIHQ})$ is a 34item self-report measure designed to identify the frequency and severity of critical incidents in the line of duty. ${ }^{13}$

The Post-Traumatic Stress Disorder Checklist-Civilian Version (PCL-C) was used to screen for post-traumatic stress symptoms. This self-report questionnaire has 17 questions that evaluate post-traumatic stress symptoms classifying them according to their intensity from "not at all" (1) to "very much" (5). Respondents rated each item according to what they considered to be the most stressful critical incident in their career.

The Peritraumatic Dissociative Experiences Questionnaire (PDEQ) is a 10-item self-report scale used to assess dissociative responses during and immediately after the chosen most stressful critical incident in the officer's career. The scored responses vary from 1 to 5 . The mean score across items was used to measure peritraumatic dissociation. ${ }^{14}$

The Peritraumatic Distress Inventory (PDI) is a 13-item self-report scale that quantifies the severity of feelings and physical sensations present during and immediately after a traumatic event. Each item is scored 0 to 4 , in a Likert-like response format, and the final score is determined by the arithmetic mean across the 13 items. ${ }^{15}$

Positive and Negative Affectivity Schedule (PANAS) consists of 20 items relating to positive and negative affectivity. According to Watson \& Clark, Positive Affect (PA) reflects "a state of high energy, full concentration, and pleasurable engagement", as opposed to Negative Affect (NA) which is a "general dimension of subjective distress and unpleasurable engagement". Subjects respond on a 5-point scale $(1=$ Not at all; $5=$ Very often) concerning the frequency of the experience of each emotional state. ${ }^{16}$

Sources of Support (SOS) is a 10-item self-report scale used to assess emotional support in a yes/no format. ${ }^{17}$

\section{Statistical analysis}

The distribution of the variables was investigated using proportions, means, and standard deviations. Log transformation was applied to variables presenting important asymmetry. Simple linear regression was performed to investigate the association between each variable, and $\mathrm{PCL}-\mathrm{C}$ symptoms and those with $\mathrm{p}$-values less than 0.20 were included in the multivariate analysis. Hierarchical multiple linear regression models were fitted, starting with socio-demographics variables, positive affect (PA), and negative affect (NA) at step one; followed by cumulative critical incident exposure score (Step 2); peritraumatic distress and dissociation (Step 3); and social support (Step 4). Variables with $\mathrm{p}$-values lower than 0.10 were maintained in the final model. Interaction terms were also evaluated.

\section{Results}

The sample of participants $(n=212)$ had a mean age of 34.8 years old $(S D=5.7)$, and about $75 \%$ were married and had more than 8 years of formal education, with an average job duration of 13.4 years $(S D=5.7)$. The mean scores for positive and negative affect were $32.8(S D=8.3)$ and 19.3 $(S D=7.5)$, respectively.
When sociodemographic variables, positive (PA) and negative (NA) affect were entered in the multivariate model, only NA and job duration showed a statistically significant positive association with PTSD symptoms (Table 1, Step 1). Number of traumatic events was also associated with an increased PCL-C score (Table 1, Step 2). When peritraumatic reactions were investigated, we found an interaction between NA and peritraumatic dissociation. The impact of dissociation on PTSD symptoms was more intense for those with higher levels of NA (Table 1, Step 3). Finally, police officers with more social support presented fewer PTSD symptoms (Table 1, Step 4). Using a hierarchical linear regression model in a cross-sectional analysis of a sample of Brazilian police of ficers $(n=212)$, we were able to explain $55 \%$ of the variance in PTSD symptoms.

\section{Discussion}

This is the first study carried out in Latin America to investigate risk factors for PTSD symptoms in police officers. Like most of the earlier studies from North America. ${ }^{7,18}$ Europe, ${ }^{2}$ Australia, ${ }^{5}$ and South Africa, ${ }^{6}$ we found that variables related to negative affect (NA), job duration, frequency of critical incident exposure, peritraumatic dissociation, and lack of social support predicted PTSD symptom severity. It is noteworthy that these five variables accounted for more than half of the variation in the PCL-C scores in our final model. A new and important observation was the demonstration of a synergistic effect between NA and peritraumatic dissociation regarding PTSD symptom severity. Although it is well-established that peritraumatic dissociation and NA independently contribute to PTSD symptom severity there is no mention of this interaction in the literature.

Negative (NA) and Positive (PA) affect are personality features, which are believed to have a biological basis. NA has been related to an impaired capacity to regulate negative emotion and to be associated with increases in the duration of distressing emotional and physical responses to traumatic situations once it has been activated. ${ }^{19}$ In fact,

Table 1 Hierarchical linear regression model predicting PTSD symptoms in a sample of male police officers $(n=212)$

\begin{tabular}{|c|c|c|c|}
\hline Level/Variables & $\begin{array}{l}\text { Coefficient } \\
\text { (SE*) }\end{array}$ & $\mathrm{p}$-value & $\begin{array}{c}\text { Accumulated } \\
\mathbf{R}^{2}\end{array}$ \\
\hline \multicolumn{4}{|l|}{ Step 1} \\
\hline NA & $1.09(0.11)$ & $<0.001$ & \\
\hline Job duration ${ }^{* *}$ & $4.43(1.51)$ & 0.004 & 0.38 \\
\hline \multicolumn{4}{|l|}{ Step 2} \\
\hline $\mathrm{ClHQ}^{* *}$ & $1.23(0.72)$ & 0.09 & 0.45 \\
\hline \multicolumn{4}{|l|}{ Step 3} \\
\hline Interaction & $0.03(0.01)$ & 0.01 & 0.55 \\
\hline \multicolumn{4}{|l|}{ NA $\times$ PDEQ } \\
\hline \multicolumn{4}{|l|}{ Step 4} \\
\hline Social support & $-0.16(0.07)$ & 0.03 & 0.55 \\
\hline
\end{tabular}


recent research demonstrated that a persistent state of threat-driven arousal has an impact on both consolidation and extinction of fear memory. ${ }^{20}$ According to fear conditioning theories, PTSD may result from an impaired extinction learning process in which individuals continue to show conditioned response when they face reminders of the trauma. Animal models and human studies have demonstrated that the failure of prefrontal cortex (PFC) to exert a top-down inhibition of the amygdala is one of the plausible mechanisms of impaired fear extinction in humans. ${ }^{21}$ Interestingly, the intentional explicit reduction of negative affect involves activation of PFC, as well as a decrease in amygdala activity. ${ }^{22}$ This pattern of findings is compatible with the idea that individuals with negative affect have a reduced capacity for extinction learning and as a result may be more prone to developing PTSD in the first place and also failing to recover from PTSD once symptomatic.

On the other hand, peritraumatic dissociation has been identified as the strongest risk factor for PTSD. ${ }^{23}$ Individuals exposed to trauma often report changes in the sense of self, time, and place during the exposure. Classically, peritraumatic dissociation is seen as a defensive mechanism that has the function of protecting against overwhelming levels of peritraumatic distress. However, there is some evidence derived from prospective studies that it is the persistence of dissociative symptoms that is the real predictor of PTSD. ${ }^{24}$ It has been hypothesized that PTSD may develop when initial inadequate encoding is not followed by information processing to address gaps and distortions in the traumatic incident representations. The interaction between NA and peritraumatic dissociation found in our study suggests that officers with higher NA would show a sustained arousal state that would elicit and maintain the early dissociative symptoms, interfering in fear encoding and processing and leading to higher scores of PTSD symptoms. This finding is consistent with the cognitive model of PTSD, which posits that it is not the traumatic event itself, but rather individual differences in coping with the sequelae that predict PTSD. ${ }^{25}$

As far as we know, this is the first study to report this synergistic effect between NA and peritraumatic dissociation in predicting severity of PTSD symptoms in a sample of police officers. However, a number of limitations are noteworthy. The main limitation of our study is the cross-sectional design, with NA and PTSD symptoms measured concurrently. Also, our results cannot be generalized to other police samples because we have studied only a convenience sample from a single capital in Brazil. Furthermore, we did not measure possible moderators of the relationship between NA and peritraumatic dissociation, such as childhood abuse, trait dissociation, and depressive symptoms. Only prospective longitudinal studies would determine if officers with higher NA assessed during academy training are at risk for greater peritraumatic dissociation at the time of exposure and are prone to more persisting dissociation after exposure, which in turn interferes with fear extinction learning. The risk factors found in this study may provide some clues to be tested in future research on how to elaborate primary prevention strategies regarding PTSD symptoms in police officers. First, in the selection procedures by identifying academy recruits with lower NA scores who would be expected to be more resilient and, alternatively, for those with higher trait NA who want to serve in high-risk professions, an specific training in behavioral and cognitive anxiety management skills to build emotion regulation may confer greater resilience. Practicing newly acquired emotion regulation skills in training exercises involving virtual reality and dry run simulations of critical incident stressors may serve to stress-inoculate trainees when confronted with real world stressors. Such training may also reduce peritraumatic dissociative responses to critical incident stressors by modulating levels of terror and horror. Runaway fear at the time of exposure is a potent trigger for dissociation. Reducing peritraumatic fear responses should also decrease fear conditioning and memory consolidation for traumatic incidents. For more vulnerable officers, with higher levels of NA and other risk factors, who respond with panic-like reactions during exposure, immediate antianxiety, behavioral and pharmacological interventions ${ }^{26,27}$ in the first hours after exposure may accelerate return to pre-incident arousal levels, reducing the risk of developing PTSD. Finally, social support provided in the workplace and in the officers' personal network should be encouraged at all times during service and mobilized immediately after exposure to critical incidents. Such initiatives may lessen the impact on police officers from repeated exposure to critical incidents over the course of their career, protecting the officers, their families, and the citizens they serve from the adverse effects of duty-related PTSD.

\section{Disclosure}

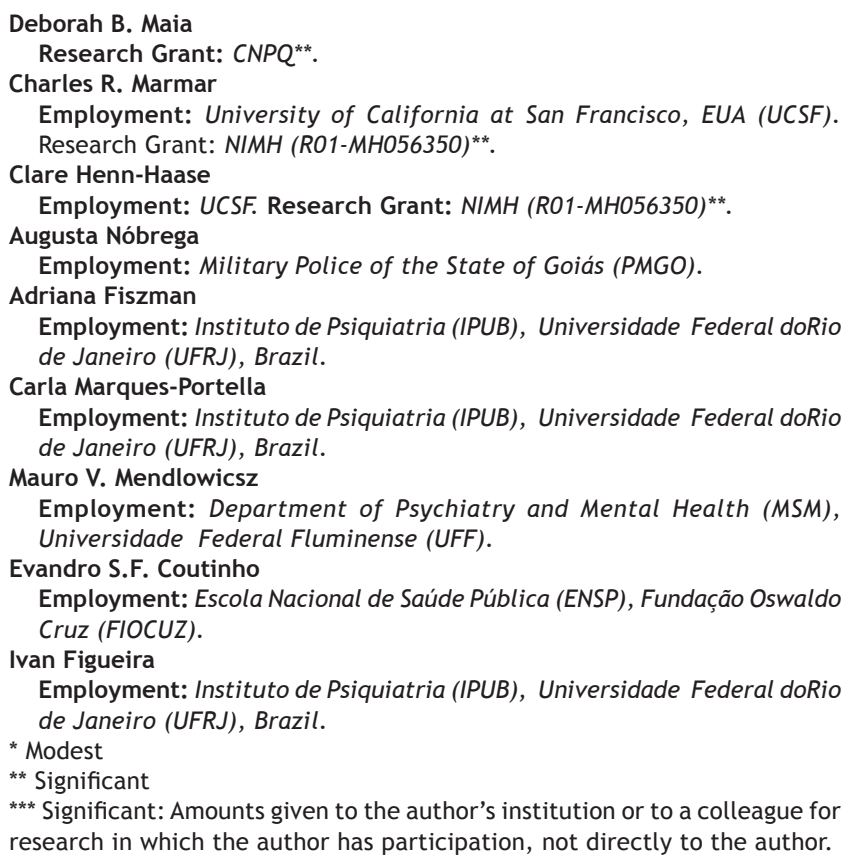

\section{References}

1. Maia DB, Marmar CR, Metzler T, Nobrega A, Berger W, Mendlowicz MV, Coutinho ES, Figueira I. Post-traumatic stress symptoms in an elite unit of Brazilian police officers: prevalence and impact on psychosocial functioning and on physical and mental health. J Affect Disord. 2007;97(1-3):241-5.

2. Carlier IV, Lamberts RD, Gersons BP. Risk factors for posttraumatic stress symptomatology in police officers: a prospective analysis. J Nerv Ment Dis. 1997;185(8):498-506. 
3. Robinson HM, Sigman MR, Wilson JP. Duty-related stressors and PTSD symptoms in suburban police officers. Psychol Rep. 1997;81(3 Pt 1):835-45.

4. Maia DB, Marmar CR, Mendlowicz MV, Metzler T, Nobrega A, Peres MC, Coutinho ES, Volchan E, Figueira I. Abnormal serum lipid profile in Brazilian police officers with post-traumatic stress disorder. J Affect Disord. 2008 ;107(1-3):259-63.

5. Hodgins GA, Creamer M, Bell R. Risk factors for posttrauma reactions in police officers: a longitudinal study. J Nerv Ment Dis. 2001;189(8):541-7.

6. Jones R, Kagee A. Predictors of post-traumatic stress symptoms among South African police personnel. S Afr J Psychol. 2005;35(2):209-224.

7. Marmar CR, McCaslin SE, Metzler TJ, Best S, Weiss DS, Fagan J, Liberman A, Pole N, Otte C, Yehuda R, Mohr D, Neylan T.Predictors of posttraumatic stress in police and other first responders. Ann N Y Acad Sci. 2006;1071:1-18.

8. Maguen S, Metzler TJ, McCaslin SE, Inslicht SS, Henn-Haase C, Neylan TC, Marmar CR. Routine work environment stress and PTSD symptoms in police officers. J Nerv Ment Dis. 2009;197(10):754-60.

9. Inslicht SS, McCaslin SE, Metzler TJ, Henn-Haase C, Hart SL, Maguen S, Neylan TC, Marmar CR. Family psychiatric history, peritraumatic reactivity, and posttraumatic stress symptoms: a prospective study of police. J Psychiatr Res. 2010;44(1):22-31.

10. Lilly MM, Pole N, Best SR, Metzler T, Marmar CR. Gender and PTSD: What can we learn from female police officers? J Anxiety Disord.2009;23(6):767-74.

11. McCaslin SE, Inslicht SS, Metzler TJ, Henn-Haase C, Maguen S, Neylan TC, Choucroun G, Marmar CR. Trait dissociation predicts posttraumatic stress disorder symptoms in a prospective study of urban police officers. J Nerv Ment Dis. 2008;196(12):912-8.

12. Meffert SM, Metzler TJ, Henn-Haase C, McCaslin S, Inslicht S, Chemtob C, Neylan T, Marmar CR. A prospective study of trait anger and PTSD symptoms in police. J Trauma Stress.2008;21(4):410-6.

13. Weiss DS, Brunet A, Best SR, Pole N, Metzler TJ, Liberman A, Fagan JA, Marmar CR. (under review). The critical incident history questionnaire: A method for measuring total cumulative exposure to critical incidents in police officers. J Traumatic Stress. Manuscript submmited for publication 2004.

14. Marmar CR, Weiss DS, Schlenger WE, Fairbank JA, Jordan BK, Kulka RA, Hough RL. Peritraumatic dissociation and posttraumatic stress in male Vietnam theater veterans. Am J Psychiatry. 1994;151(6):902-7.
15. Brunet A, Weiss DS, Metzler TJ, Best SR, Neylan TC, Rogers C, Fagan J, Marmar CR. The Peritraumatic Distress Inventory: a proposed measure of PTSD criterion A2. Am J Psychiatry. 2001;158(9):1480-5.

16. Watson D, Clark LA, Tellegen A. Development and validation of brief measures of positive and negative affect: the PANAS scales. J Pers Soc Psychol. 1988;54(6):1063-70.

17. Kulka R, Schlenger W, Fairbank J, Jordan B, Hough R, Marmar C. Assessment of posttraumatic stress disorder in the community: Prospects and pitfalls from recent studies of Vietnam Veterans. J Consult Clin Psychol. 1991;3:547-60.

18. Martin M, Marchand A, Boyer R, Martin N. Predictors of the development of posttraumatic stress disorder among police officers. J Trauma Dissociation. 2009;10(4):451-68.

19. Davidson RJ. Affective Neuroscience and psychophysiology: Toward a synthesis. Psychophysiology. 2003;40(5):655-65.

20. McGaugh JL. The amygdala modulates the consolidation of memories of emotionally arousing experiences. Annu Rev Neurosci. 2004;27:1-28.

21. Phelps EA, Delgado MR, Nearing KI, LeDoux JE. Extinction learning in humans: role of the amygdala and vmPFC. Neuron. 2004;43(6):897-905.

22. Goldin PR, McRae K, Ramel W, Gross JJ. The neural bases of emotion regulation: reappraisal and suppression of negative emotion. Biol Psychiatry. 2008;63(6):577-86.

23. Ozer EJ, Best SR, Lipsey TL, Weiss DS. Predictors of posttraumatic stress disorder and symptoms in adults: a meta-analysis. Psychol Bull. 2003;129(1):52-73.

24. Briere J, Scott C, Weathers F. Peritraumatic and persistent dissociation in the presumed etiology of PTSD. Am J Psychiatry. 2005;162(12):2295-301.

25. Halligan SL, Michael T, Clark DM, Ehlers A. Posttraumatic stress disorder following assault: the role of cognitive processing, trauma memory, and appraisals. J Consult Clin Psychol. 2003;71(3):419-31.

26. Vaiva G, Ducrocq F, Jezequel K, Averland B, Lestavel P, Brunet A, Marmar CR. Immediate treatment with propranolol decreases posttraumatic stress disorder two months after trauma. Biol Psychiatry. 2003;54(9):947-9.

27. Roberts NP, Kitchiner NJ, Kenardy J, Bisson JI. Systematic review and meta-analysis of multiple-session early interventions following traumatic events. Am J Psychiatry. 2009;166(3):293-301.

28. Ruggiero KJ, Del Ben K, Scotti JR, Rabalais AE. Psychometric properties of the PTSD Checklist-Civilian Version. J Trauma Stress. 2003;16(5):495-502. 